inflammatory drugs: population based observational study and case-control study. BMJ 2001:322:266-70.

10 Li DK, Odouli R, Wi S, Janevic T, Golditch I, Bracken TD, et al. A population-based prospective cohort study of personal exposure to magnetic fields during pregnancy and the risk of miscarriage. Epidemiology 2002;13:9-20.

11 Anderson PK, Gill RD. Cox's regression model for counting processes: a large sample study. Ann Stat 1982;10:1100-20.

12 Therneau TM, Grambsch PM. Modeling survival data: extending the Cox model. New York: Springer-Verlag, 2000.

13 Howards PP, Hertz-Picciotto I. Spontaneous abortion and left truncation [abstract] Am J Epidemiol 2002;155(11):S35.
14 Van der Weiden RM, Helmerhorst FM, Keirse MJ. Prostanoid excretion in incipient singleton and twin pregnancies. Am J Obstet Gynecol 1996;174:1614-7.

15 Van der Weiden RM, Helmerhorst FM, Keirse MJ. Influence of prostaglandins and platelet activating factor on implantation. Hum Reprod 1991;6:436-42.

16 Van der Weiden RM, Wouters JM. Infertility may sometimes be associated with non-steroidal anti-inflammatory drug consumption. $\mathrm{Br} J$ Rheumatol 1997;36:605.

(Accepted 2 June 2003)

\section{Doctors' knowledge of radiation exposure: questionnaire study}

\author{
S Shiralkar, A Rennie, M Snow, R B Galland, M H Lewis, K Gower-Thomas
}

\section{Introduction}

Despite the small but definite risk to patients' health, investigations involving radiation are an accepted and fundamental part of medical practice. In the United Kingdom an estimated 100-250 deaths occur each year from cancers directly related to medical exposure to radiation. ${ }^{1}$ In March 2000, the UK secretary of state issued new regulations that emphasised the importance and dangers of radiation. ${ }^{2}{ }^{3}$

We investigated the level of knowledge doctors have concerning radiation doses received by patients when they undergo commonly requested radiological investigations.

\section{Participants, methods, and results}

We compiled a questionnaire listing the most commonly requested radiological investigations. Participants were asked to identify the average dose of radiation received when a person underwent a standard chest $\mathrm{x}$ ray. This was then used to represent a single dose of radiation, and doctors were asked to estimate the equivalent doses of radiation for various radiological investigations (table). all different grades from two separate hospitals (South Wales and Oxford) to take part in the study and interviewed each doctor on a one to one basis. All doctors agreed to complete the questionnaire. There was no negative marking. We accepted a deviation of $20 \%$ above and below the correct value (wider variations were allowed for those procedures for which the radiation dose can vary enormously). Correct answers to the questions were derived from information available on the internet ${ }^{4}$ and counter checked with the Royal College of Radiologists. ${ }^{5}$

We interviewed 40 senior house officers, 40 specialist registrars, 40 consultants, and 10 consultant radiologists. None of them knew the approximate dose of radiation received by a patient during a chest $\mathrm{x}$ ray or even the measurement in units of radiation $(0.02$ $\mathrm{mSv}$ ). The minimum score was $0 \%$ and the maximum score was $59 \%$. Five doctors (4\%) gave no correct answers. The estimated doses of radiation were much lower than the correct doses. For example, a patient
We asked a convenience sample of 130 doctors at undergoing an arteriogram of the leg would receive 400 times the radiation of a chest $\mathrm{x}$ ray, but the average mean answer was 26 times-that is, doctors were submitting their patients to a radiation dose that was 16 times larger than they thought it was. The average mean dose of irradiation was six times the quantity estimated by the doctor.

Overall, $97 \%$ of the answers were underestimates of the actual dose; six (5\%) doctors did not realise that ultrasound does not use ionising radiation; and 11 $(8 \%)$ did not realise that magnetic resonance imaging does not use ionising radiation.

\section{Comment}

In a convenience sample of doctors few had any knowledge about the level of radiation that their patients were exposed to during radiological investigations. Most patients entering hospital will have at least one $\mathrm{x}$ ray investigation and usually many more subsequent $\mathrm{x}$ rays. It is well known to both the lay public and to medical professionals that although radiological investigations are valuable, they represent a small but definite potential risk to health through

Equivalent number of doses of radiation for most commonly requested investigations. Dose for chest $x$ ray used as single unit dose of radiation. Figures are numbers (percentage) of doctors with correct answer for each investigation

\begin{tabular}{lcc} 
Radiological investigation & Equivalent $\mathbf{N}$ of chest $\mathbf{x}$ rays & No of correct answers $(\mathbf{n}=\mathbf{1 3 0})$ \\
\hline Abdominal $x$ ray & 75 & $2(1.5)$ \\
\hline Lumbar spine $x$ ray & 120 & $3(2)$ \\
\hline Thoracic spine $x$ ray & 50 & $4(3)$ \\
\hline Barium swallow & 100 & $6(5)$ \\
\hline Peroperative cholangiogram & 65 & $3(2)$ \\
\hline Fixation of fractured neck of femur & 45 & $10(8)$ \\
\hline Ultrasound of abdomen & 0 & $124(95)$ \\
\hline CT of abdomen & 400 & $8(6)$ \\
\hline Spiral CT of abdomen & 300 & $9(7)$ \\
\hline MRI of abdomen & 0 & $119(92)$ \\
\hline MRI of knee & 0 & $119(92)$ \\
\hline MRI of spine & 0 & $119(92)$ \\
\hline Leg arteriogram & 400 & 0 \\
\hline Renal arteriogram & 80 & $1(1)$ \\
\hline Thyroid isotope scan & 50 & $8(6)$ \\
\hline White cell scan & 150 & $2(1.5)$ \\
\hline
\end{tabular}

$\mathrm{CT}=$ computed tomography; MRI=magnetic resonance imaging.

Russells Hall Hospital, Dudley, West Midlands DY1 $2 \mathrm{HQ}$

S Shiralkar consultant surgeon Royal Berkshire Hospital, Reading RG1 5AN A Rennie senior house officer in general surgery

R B Galland consultant surgeon continued over

BMJ 2003;327:371-2 exposure to ionising radiation. 
Royal Glamorgan

Hospital,

Llantrisant

CF72 8XR

M Snow

senior house officer in

general surgery

M H Lewis

consultant surgeon

K Gower-Thomas

consultant radiologist

Correspondence to:

M H Lewis

mike.lewis@pr-tr.

wales.nhs.uk
The interviewed doctors came from two hospitals in two different regions. Therefore our results may not apply throughout the United Kingdom, but it does seem that most doctors have no idea as to the amount of radiation received by patients undergoing commonly requested investigations, despite them all having undertaken the radiation protection course. This lack of awareness of the degree of exposure to ionising radiation becomes particularly pertinent when we consider the number of patients who receive inappropriate or repeat examinations.

Contributors: SS, AR, and MS questioned the selection of doctors on a one to one basis in the South Wales and Oxford region. SS, MHL, RBG, and KGT wrote and contributed to the final version of the paper. KGT is the guarantor.
Funding: None.

Competing interests: None declared.

1 Royal College of Radiologists and National Radiological Protection Board. Patient dose reduction in diagnostic radiology. Documents of the National Radiological Protection Board 1990;1:No 3.

2 The Ionising Radiation (Medical Exposure) Regulations 2000. www.doh.gov.uk/irmer.htm (accessed 14 Oct 2002).

3 Statutory instrument 2000 number 1059. The Ionising Radiation (Medical Exposure) Regulations 2000. www.legislation.hmso.gov.uk/si/si2000/ 20001059.htm (accessed 14 Oct 2002).

4 Health Physics Society. www.hps.org/publicinformation/asktheexperts. cfm (accessed 12 Nov 2001).

5 Royal College of Radiologists. Making the best use of department of clinical radiology: guidelines for doctors. 4 th ed. London: Royal College of Radiologists, 1998.

(Accepted 14 May 2003)

\section{Is asking patients in palliative care, "Are you depressed?" appropriate? Prospective study}

Mari Lloyd-Williams, Mick Dennis, Fiona Taylor, Idris Baker

Department of

Primary Care,

University of

Liverpool Medical

School, Liverpool

L69 3GB

Mari

Lloyd-Williams

senior lecturer in

palliative medicine

Department of

Psychiatry,

University of

Leicester, Leicester

General Hospital,

Leicester LE5 4PW

Mick Dennis

senior lecturer

LOROS Hospice,

Leicester LE3 9QE

Fiona Taylor

research student

Idris Baker

registrar

Correspondence to:

M Lloyd-Williams

mlw@liv.ac.uk

BMJ 2003;327:372-3
Depression is a serious problem that affects about a quarter of patients in palliative care. ${ }^{1}$ Diagnosing depression is difficult because most patients are understandably sad. Lack of recognition of depression can lead to further morbidity and a detrimental effect on the quality of life. ${ }^{2}$

Screening for depression attracts wide interest, but as patients are frail and unwell, a screening tool needs to be brief. Asking North American patients in palliative care the single question, "Are you depressed?" had perfect sensitivity and specificity and $100 \%$ positive predictive value compared with the schedule for affective disorders. ${ }^{3}$ Other studies of patients with stroke and elderly patients found that a single statement with a "yes" or "no" response correctly classified more than $80 \%$ of people as depressed or not depressed. $^{45}$

\section{Participants, methods, and results}

Patients were eligible to participate if they received only palliative and supportive day care; 106 were eligible to participate in the study during six months. A total of 74 patients consented to participate; we got baseline demographic information on age, ethnicity, diagnosis, past history of depression, and performance status (all patients had an Eastern Cooperative Oncology Group (ECOG) performance of 2 or 3-that is, physical function was limited). Age, sex, disease state, and performance status did not differ between consenters and non-consenters. Patients were aged 28-89 (mean 68) years.

We compared the result of the single question, "Are you depressed?" with a semistructured clinical psychiatric interview based on the criteria of the fourth edition of the Diagnostic and Statistical Manual of Mental Disorders. We calculated the sensitivity, specificity, and the positive and negative predictive values.
Number of patients answering the question, "Are you depressed?" and results of their clinical interview

\begin{tabular}{lcc} 
Clinical interview (Diagnostic and Statistical & \multicolumn{2}{c}{ Are you depressed? } \\
\cline { 2 - 3 } Manual of Mental Disorders, 4 th ed) & Yes & No \\
\hline Depressed & 11 & 9 \\
\hline Not depressed & 14 & 40 \\
\hline Total & 25 & 49
\end{tabular}

We found that $27 \%$ of patients had depression (95\% confidence interval $17 \%$ to $37 \%$ ). To the single question, "Are you depressed?" 25 patients responded "yes"; in the clinical interview we found that 11 were depressed. Nine patients who replied "no" to the question were considered depressed by clinical interview (table). A yes answer had a sensitivity of $55 \%$ (34\% to $77 \%)$ and specificity of $74 \%$ (61\% to $84 \%$ ) and positive and negative values of $44 \%$ and $82 \%$ respectively.

\section{Comment}

The single question, "Are you depressed?" is widely believed to successfully screen for depression in palliative care-many clinicians use it routinely-but it does not have the perfect sensitivity and specificity in the UK population that it achieved in North America. ${ }^{3}$

Although this is a small study, it is larger than many other studies concerning patients in palliative care. A quarter of patients had depression. The single question in this study correctly identified just over half of the patients diagnosed as depressed and approximately three quarters of the patients diagnosed as nondepressed.

In the North American study, the researchers included the single question, "Are you depressed?" in the schedule of the interview, which may have biased the results. Our results are also less favourable than those found in a study of stroke patients and elderly patients which compared the discriminating power of 